physiotherapy, number of re-fractures, BMI, parent hip fracture, current smoking, corticotherapy, rheumatoid arthritis, secondary osteoporosis, alcohol, history of falls, anti-osteoporotic treatment, Katz index of independence in activities of daily living and Charlson comorbidity index. All FRAX ${ }^{\circledR}$ variables were defined as established in this algorithm.

Results: A total of 130 patients satisfied the inclusion criteria, with a mean age of $82 \pm 8,7$ years, $69 \%$ being female). Mortality rates were of $30 \%$ and $41 \%$ at 1 and 3 years after HF respectively (Fig.1). Age, physiotherapy, parent fractured hip, corticotherapy, alcohol consumption ( $>3 /$ day) and Charlson índex were statistically significant predictors of mortality at 3 years in multivariable analysis (Tab.1). Re-fracture rates at 1 and 3 years after the index fracture was 3,8\% and $11 \%$ respectively (Fig.1). We were unable to identify any statistically significant predictors of re-fracture.
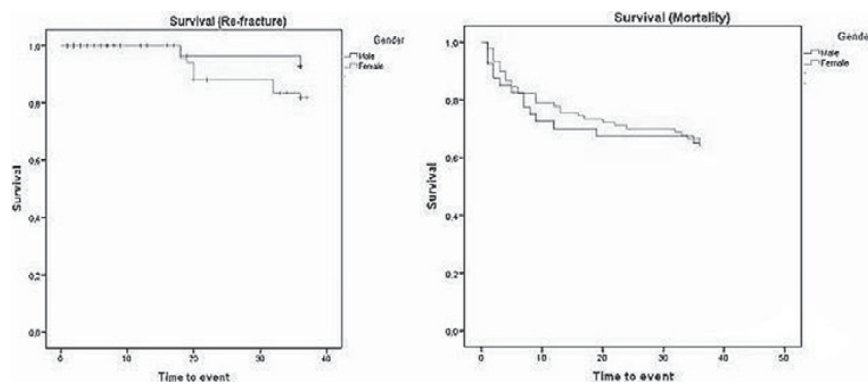

Conclusions: We concluded that HF have a great impact on the older population, leading to high morbidity and mortality. In our study, age, physiotherapy, parent hip fracture, corticotherapy, alcohol consumption and Charlson índex are related with increasing mortality in patients who suffered a fagility HF.

Disclosure of Interest: None declared

DOI: 10.1136/annrheumdis-2017-eular.4473

\section{FRI0559 CORRELATION OF THE FRACTURE RISK ASSESSMENT TOOL (FRAX) AND ASYMPTOMATIC MORPHOMETRIC VERTEBRAL DEFORMITIES IN HIV-INFECTED PATIENTS}

M. Llop Vilatella ${ }^{1}$, C. Medina Quiñones ${ }^{1}$, C. Macía Villa ${ }^{1}$, W.A. Sifuentes Giraldo ${ }^{1}$, M. Vázquez Díaz ${ }^{1}$, J.L. Casado Osorio ${ }^{2} .{ }^{1}$ Rheumatology; ${ }^{2}$ Infectious diseases, Hospital Universitario Ramón y Cajal, Madrid, Spain

Background: Patients infected with the human immunodeficiency virus (HIV) have a high rate of low bone mineral density (BMD) and is thought to be multifactorial. Some instruments have been developed to estimate the risk of osteoporotic fracture in the general population such as the WHO Fracture Risk Assessment Tool (FRAX), which allows calculating the 10-year probability of fractures in men and women from clinical risk factors with or without the measurement of femoral neck BMD. The cut-off values for high risk of hip fracture $>3 \%$ and for major osteoporotic fracture $>20 \%$. Although FRAX has been validated in multiple large cohorts, still there are no clear recommendations of its use in HIV-infected patients older than 50 years.

Objectives: To evaluate the utility of FRAX tool in the prediction of risk of vertebral morphometric deformity (MVD) in HIV-infected patients over 50 years old seen in a Spanish tertiary care center.

Methods: We performed a cross-sectional study in HIV-infected patients with age 50 years treated in our centre during the period 2014-2016. Demographics and risk factors were collected through a specific survey. FRAX was calculated adding HIV as a cause of secondary osteoporosis in all patients with and without BMD measured by dual-energy X-ray absorptiometry scan (DXA). The MVD were assessed using the Genant's semiquantitative method. The sensitivity and specificity of the test were assessed and correlations made with the presence of MVD.

Results: A total of 121 patients were included, 34 women $(28 \%)$, with a mean age of 54.1 years (range: $50-75$ ). MVD was detected in 25 cases (21\%). The patients presented with a mean BMl of $23.7 \mathrm{~kg} / \mathrm{m}^{2}, 33 \%$ were smokers, $7 \%$ had a consumption of $>3$ doses of alcohol per day, $9 \%$ had a family history of hip fracture but no patient presented with previous history of fracture, corticoid treatment or rheumatoid arthritis. The mean FRAX score for major osteoporotic fracture without BMD was of $2.29(1.1-8.5)$, there were 2 patients above 7 and any above 10; the mean FRAX score for hip fracture without BMD was of 0.64 (0.1-3.9), 2 patients were above 3. With DXA, osteoporosis in femoral neck was detected in $8 \%$ and in the lumbar spine in $30 \%$, while femoral neck osteopenia was detected in $64 \%$ and in the lumbar spine in $45 \%$. Including DXA data, the mean FRAX score for major osteoporotic fracture was 2.52 (0.2-8.2), 2 patients were above 7 , and for hip fracture the mean FRAX score was $0.67(0.01-4.4)$, with 2 patients above 3 . The values of FRAX with DXA or without DXA were very similar, with a variation of -0.4 for the mean value of major osteoporotic fracture and +0.03 for the mean value of hip fracture. In ROC curve, a value above 1 in FRAX for hip fracture with DXA, detected 9 MVD of 29 patients (sensitivity $38 \%$, specificity $80 \%$ ), a value above 2 detected 4 MVD of 10 patients (sensitivity $17 \%$, specificity $93 \%$ ) and a value of 3 detected 1 MVD of 2 patients (sensitivity $4 \%$, specificity $99 \%)$.
Conclusions: The FRAX tool does not identify properly the HIV-infected patients older than 50 years with MVD as well as the patients who need DXA. An alternative could be to perform X-rays of thoracic and lumbar spine as a screening method in HIV-infected patients with risk factors.

Disclosure of Interest: None declared

DOI: 10.1136/annrheumdis-2017-eular.5205

\section{FRI0560 PREDICTORS OF FRACTURES IN FEMALE PATIENTS WITH ANOREXIA}

M. Rahm, M. Bukhari. Rheumatology, Royal Lancaster Hospital, Lancaster, United Kingdom

Background: Anorexia Nervosa (AN) is an eating disorder characterised by extremely low body weight and body image distortion. It is more common in females and is expected to become increasingly more prevalent. Numerous studies have found AN to have a detrimental effect on bone health. The evidence shows that anorexia is associated with reduced bone mass and strength which increases fracture risk. Few staudes have looked at other predictors of fracture in these patients.

Objectives: The aim of this study was to determine whether further predictors of fracture could be found in female patients suffering from anorexia nervosa (AN). Methods: Female patients with anorexia refereed for a bone mineral density (BMD) DEXA scan from June 2006 to October 2014 were identified. This cohort of patients was split into two subgroups depending on their fracture status. Demographics collected on scanning and factors such as age at DEXA scan, height, weight, body fat percentage, BMI, lumbar spine L1-L4 BMD and femoral neck BMD were used to compare the fracture group against the controls. Categorical variables such as smoking, comorbidities (Rheumatoid arthritis), alcohol, family history and steroid use were compared using chi squared test and the $T$ test was used tompare continous variables. Logistic regression models were used to model fractures unadjusted and adjusting for age at scan.

Results: A total of 193 female patients with anorexia were included: 45 (23.3\%) had sustained a fracture. The results of statistical analysis are shown in Table 1. The data showed there is a significant association with having a low femoral neck BMD and increased fracture risk OR $0.036(95 \%, \mathrm{Cl} 0.003,0.497)$. The case group was also significantly taller OR $1.061(95 \%, \mathrm{Cl} 1.009,1.117)$ and older $\mathrm{P}$ value 0.0027 (95\% combined $\mathrm{Cl} 39.193,42.682)$. There was no correlation with any of the categorical variables and fracture risk, see Table 2 for results.

Table 1. Results of statistical analysis of continuous variables

\begin{tabular}{lccc}
\hline Characteristic & Significance (P value) & Cases with fractures & Control group \\
\hline Age at scan (years) & 0.0027 & $45.71 \pm$ SD 10.36 & $39.49 \pm$ SD12.46 \\
Height $(\mathrm{cm})$ & 0.021 & $165.08 \pm$ SD7.45 & $162.66 \pm$ SD6.82 \\
Weight $(\mathrm{kg})$ & 0.129 & $58.16 \pm$ SD13.68 & $53.73 \pm$ SD11.83 \\
Body Fat $(\%)$ & 0.536 & $16.36 \pm$ SD11.75 & $13.62 \pm$ SD 10.28 \\
BMl & 0.601 & $21.24 \pm$ SD4.31 & $20.31 \pm$ SD4.43 \\
Lumbar spine $(\mathrm{L} 1-\mathrm{L} 4)\left(\mathrm{g} / \mathrm{cm}^{2}\right)$ & 0.053 & $0.98 \pm$ SD0.18 & $1.03 \pm$ SD0.14 \\
Femoral neck BMD $\left(\mathrm{g} / \mathrm{cm}^{2}\right)$ & 0.013 & $0.81 \pm$ SD0.15 & $0.86 \pm$ SD0.14 \\
\hline
\end{tabular}

Table 2. Results of statistical analysis of categorical variables

\begin{tabular}{lccc}
\hline Characteristic & Cases with fracture (45) & Control group (148) & Significance (P value) \\
\hline Smoker & $28.9 \%(13)$ & $34.46 \%(51)$ & 0.445 \\
RA & $2.22 \%(1)$ & $0.68 \%(1)$ & 0.349 \\
Alcohol & $8.89 \%(4)$ & $8.78 \%(13)$ & 0.524 \\
Family history & $31.11 \%(14)$ & $22.97 \%(34)$ & 0.403 \\
Steroid & $15.56 \%(7)$ & $8.78 \%(13)$ & 0.197 \\
\hline
\end{tabular}

Conclusions: This study demonstrates that fractures in female patients with anorexia are more likely to occur in those who are taller, older at DEXA scan and in those who have a lower femoral neck BMD. This would inidcate that cortiocal bone loss and taller stature are indepent risks in this cohort. Further work using vitamin $\mathrm{D}$ levels as a risk should be performed.

Disclosure of Interest: None declared

DOI: 10.1136/annrheumdis-2017-eular.3778

\section{FRI0561 SAFETY OF DENOSUMAB IN POST-MENOPAUSAL OSTEOPOROSIS AND IN CANCER: A SYSTEMATIC REVIEW AND META-ANALYSIS}

M. Aubailly ${ }^{1}$, T. Barnetche ${ }^{2}$, B. Combe ${ }^{1}$, C. Gaujoux-viala ${ }^{3}$, C. Lukas ${ }^{1}$,

J. Morel ${ }^{1}, \mathrm{H}$. Che ${ }^{1} .{ }^{1} \mathrm{CHU}$ lapeyronie, Montpellier; ${ }^{2} \mathrm{CHU}$ bordeaux, Bordeaux; ${ }^{3} \mathrm{CHU}$ Nîmes, Nîmes, France

Background: Denosumab is a RANK ligand antibody (1) used for the treatment of post-menopausal osteoporosis (OP) and prevention of bone metastases complications $(2,3)$

Objectives: The aim of this meta-analysis was to assess the safety of Denosumab. Methods: Data sources included MEDLINE, EMBASE, Cochrane Library, and recent abstracts from ACR and EULAR congresses were searched until March 2016. Randomized controlled trials comparing the safety of Denosumab to placebo or bisphosphonates (BP) in postmenopausal OP and in cancer (either cancer with bone metastases or with hormone therapy) were selected. Data were 
extracted by one investigator, confirmed by another, and pooled in meta-analysis using Review Manager software (Cochrane collaboration).

Results: 6136 articles were of potential interest, and 19 met the inclusion criteria. 7 articles compared the safety of Denosumab to BP in post-menopausal OP. There was no significant difference when comparing Denosumab with bisphosphonates in any adverse events $(A A E)(R R=0.98,95 \% \mathrm{Cl}=0.95-1.01)$ serious adverse event (SAE) $(\mathrm{RR}=1.04,95 \% \mathrm{Cl}=0.81-1.33)$. Regarding Denosumab versus placebo in post-menopausal OP, 7 studies were included and there was no significant difference in $A A E(R R=0.98,95 \% C l=0.94-1.01)$, SAE ( $R R=1.03,95 \% C l=0.96-1.11)$, however cellulitis was more frequently found with Denosumab (RR=8.03, 95\% $\mathrm{Cl}=1.44-44.79)$. No cases of osteonecrosis of the jaw (ONJ) had been reported. 5 articles were pooled to compare Denosumab with BP in patients with bone metastases and no significant difference was found in AAE $(\mathrm{RR}=0.99,95 \% \mathrm{Cl}=0.98$ 1.00), SAE ( $R R=0.99,95 \% \mathrm{Cl}=0.95-1.03)$, and ONJ ( $R R=1.40,95 \% \mathrm{Cl}=0.92-$ 2.13). 4 articles were selected concerning patients treated with placebo or Denosumab in breast and prostate cancer without bone metastases. Although no significant difference was found in AAE (RR 1.01, 95\% Cl=0.99-1.03), use of Denosumab was associated with a significantly increased risk of hypocalcemia (RR $5.20,95 \% \mathrm{Cl}=1.34-20.13$ ) and of cholecystitis (RR 3.43, 95\% Cl=1.01-11.69) Conclusions: In post-menopausal OP, Denosumab had a relatively good safety profile although significantly more cellulitis occurred when compared with placebo. For patient with cancer, Denosumab was associated with more hypocalcemia and cholecystitis than placebo.

\section{References:}

[1] Boyle WJ, Simonet WS, Lacey DL. Osteoclast differentiation and activation. Nature. 2003;423(6937):337-42

[2] Brown JP, Prince RL, Deal C, Recker RR, Kiel DP, de Gregorio LH, et al. Comparison of the effect of denosumab and alendronate on BMD and biochemical markers of bone turnover in postmenopausal women with low bone mass: a randomized, blinded, phase 3 trial. J Bone Miner Res Off J Am Soc Bone Miner Res. 2009;24(1):153-61.

[3] Lipton A, Fizazi K, Stopeck AT, Henry DH, Smith MR, Shore N, et al. Effect of denosumab versus zoledronic acid in preventing skeletal-related events in patients with bone metastases by baseline characteristics. Eur J Cancer Oxf Engl 1990. 2016;53:75-83.

Disclosure of Interest: None declared

DOI: 10.1136/annrheumdis-2017-eular.3900

\section{FRI0562 PROPORTION OF HIP AND NON-HIP MAJOR FRACTURES: COSTS AND QUALITY OF LIFE}

M.L. Marques, A. Marques, A. Daniel, L. Brites, J.A.P. da Silva. Rheumatology Department, CHUC, Coimbra, Portugal

Background: FRAX ${ }^{\circledR}$ country specific risk estimates are a mainstay of current treatment decisions and public health policies in osteoporosis. Because the registries of major non-hip fractures (NHF) is poor in most countries, this estimate is based on the gender- and age-specific ratio of hip fractures (HF) to NHF observed in a prospective population-based study performed in Malmo, Sweden ${ }^{1}$. FRAX ${ }^{\circledR}$ presumes, therefore, that the ratio of incidence and cost of hip/major osteoporotic fractures is similar, in every country, to that observed in Sweden. This major assumption has seldom been questioned.

Objectives: This retrospective single-centre observational study aimed to assess the proportion of HF vs. NHF and the impact of wrist and vertebral fractures, in terms of costs and health-related quality of life ( $\mathrm{HrQ} \mathrm{LL}), 1$ year after the fracture in Portugal.

Methods: We revised the records of all patients observed in an emergency department through a period of 3 months and included those aged $50+$ diagnosed with a fragility (low energy) HF or NHF. A telephone interview was conducted in a randomly selected subsample of patients from each type of fracture 1 year after fracture. A questionnaire with socio-demographic data, resource consumption over 1st year and HrQol (EQ-5D) was applied to patients or their caregivers. Direct and indirect costs were estimated from a societal perspective.

Results: In the study period, 1760 patients were observed by the orthopaedics emergency team. Of these, 435 patients had suffered a fracture (129 fragility $\mathrm{HF}, 152 \mathrm{NHF}$ and 154 fractures that were not considered low-trauma and were therefore excluded). Humerus fractures were also excluded, to mirror the Swedish study. The randomly selected subsample of patients consisted of 66 NHF (55 with wrist and 11 with clinical vertebral fractures). Patients were mostly females in all types of fractures (58\% to $82 \%)$. The mean age at fracture was higher in HF (81.6 \pm 8.59 vs. $69.1 \pm 10.06)$. Falls were the cause of fracture in $97 \%$ of cases. Inpatient care was provided to $100 \%$ of HF patients vs. $25.8 \%$ of NHF patients. The proportion of fractures, average fracture-related costs for the 1st year, and the mean impact upon HrQoL are shown in Table 1.
Conclusions: The proportion HF/NHF observed in Portugal is similar to the Swedish reference values $(0.44 / 0.56)$. The highest cost were attributed to hip fractures in both countries, followed by vertebral fractures and lastly by wrist fractures. The HrQoL mean loss was higher for vertebral fractures in both countries. The reported costs of vertebral fractures are much higher than in Portugal which may significantly affect the calculation of cost-effectiveness thresholds for intervention.

References:

[1] Borgström F, et al. Osteoporos Int. 2006;17(5):637-50.

[2] Marques A, et al. Osteoporos Int. 2015 Nov;26(11):2623-30.

Disclosure of Interest: None declared

DOI: 10.1136/annrheumdis-2017-eular.6942

\section{FRI0563 USE OF TERIPARATIDE AS A CALLUS ACCELERATOR IN NONUNION OF LOWER LIMB}

M. Muratore ${ }^{1}$, O.E. Casilli ${ }^{1}$, V. Russi ${ }^{2}$, P. Pichierri ${ }^{2}$, L. Meccariello ${ }^{2}$, L. Quarta ${ }^{1}$, E. Quarta ${ }^{1}$, G. Rollo ${ }^{2}$, M. Filipponi ${ }^{2}$. U.O. Reumatologia- P.O. "V. Fazzi" Lecce; ${ }^{2}$ U.O. Ortopedia- P.O. "V. Fazzi" Lecce, LECCE, Italy

Background: The use of teriparatide in fracture management by high-energy trauma with loss of bone substance and muscle and skin with possible nerve/vascular lesions is poorly documented. The aim of our study is to evaluate how the intermittent administration of teriparatide may affect the bone consolidation newly generated and compression in patients with bone loss and my-skin during treatment reconstruction with the technique of resection Ilizarov-lengthening.

Objectives: In large trauma or in the outcomes of these, in which there is loss of bone substance and muscle and skin the technique of reconstruction of llizarov $(1 \mathrm{~mm} /$ day) is used; the main problem is the long time required to reach complete healing with optimal bone consolidation newly generated and the compression outbreak of ensuring the mechanical strength necessary to be able to remove the external fixator (1). The rationale of this study, therefore, was to evaluate the influence of treatment with teriparatide, administered subcutaneously 1 dose 1 time/day from a pre-filled syringe of $20 \mathrm{mcg}$ and for a period of three months, the evolution radiographic, on the healing time and the external fixator removal and on the functional recovery quality in multiple trauma patient.

Methods: In our prospective study, we evaluated two groups of patients: Group 1: 9 patients treated with PTH during bone transport; Control Group 2: 10 patients treated with bone transport.

Results: The group 1 compared to the 2 (control group) showed a bone radiographic progression slower newly-generated in the first month of administration of teriparatide; subsequently it was observed an acceleration of bone maturation but not uniform; after about 3 months, the bone maturation accelerates further also at the level of the compression outbreak if already in compression, allowing the removal of the fixator about 1.5 months earlier than the estimated time. This is due to the reduction of the time allowed for "elongation stage" bone that physiologically is around $1 \mathrm{~mm} /$ day, thus ensuring an optimal functional recovery. Conclusions: The action of teriparatide (2) on bone healing is derived from increased differentiation of cells responsible for bone callus formation, chondrocytes and osteoblasts, mediated in part by increased activation of genes that produce the Wnt, Osterix and Runx2, all fundamental elements in the osteoblastogenesis. Although the sample examined is small for the specificity of the described treatment, the data reported showed that the intermittent administration of teriparatide is able to accelerate the timing for the "elongation stage" bone and therefore the bone healing and reconstructive treatment times in serious loss of substance.

\section{References:}

[1] Treatment of complex nonunion of the shaft of the tibia using llizarov technique and its functional outcome. Sahu RL, Ranjan R. Niger Med J. 2016 Mar-Apr;57(2):129-33

[2] Stimulation of fracture-healing with systemic intermittent parathyroid hormone treatment. Barnes GL, Kakar S, Vora S, Morgan EF, Gerstenfeld LC, Einhorn TA. J Bone Joint Surg Am. 2008;90(Suppl 1):120-127.

Disclosure of Interest: None declared

DOI: 10.1136/annrheumdis-2017-eular.4796

Abstract FRI0562 - Table 1. Proportion, costs and HrQoL per type of fracture in Portugal and Sweden

\begin{tabular}{|c|c|c|c|c|c|c|}
\hline & \multicolumn{3}{|c|}{ Portugal } & \multicolumn{3}{|c|}{ Sweden } \\
\hline Type of fracture & Hip & Wrist & Vertebral & Hip & Wrist & Vertebral \\
\hline Number $(\%)$ of observed fragility fractures & $129(51)$ & $100(39)$ & $26(10)$ & $278(44)$ & $276(43)$ & $81(13)$ \\
\hline Costs $(€)$ per patient, 1st year $(95 \% \mathrm{Cl})$ & $13,434(12,290 ; 14,576)^{\star}$ & $2220(1626 ; 2575)$ & $5390(1947 ; 6412)$ & $14,221(12,912 ; 15,790)$ & $2147(1923 ; 2477)$ & $12,544(10,059 ; 16,324)$ \\
\hline Weighed mean cost $(€)$ & 13,434 & \multicolumn{2}{|c|}{2867} & 14,221 & \multicolumn{2}{|r|}{4558} \\
\hline Average loss of HrQoL mean $(95 \% \mathrm{Cl})$ & $0.29(0.22 ; 0.36)^{\star}$ & $0.11(0.06 ; 0.15)$ & $0.38(0.24 ; 0.52)$ & $0.23(0.21 ; 0.26)$ & $0.10(0.08 ; 0.12)$ & $0.30(0.25 ; 0.36)$ \\
\hline
\end{tabular}

*Based on data published elsewhere ${ }^{2}$. 